\title{
COMUNICAÇÃO ORGANIZACIONAL: CONTEXTOS E PERSPECTIVAS
}

Kary Emanuelle Reis Coimbra kary.kk@hotmail.com

Mestranda em Administração pelo Centro de Pós-Graduação e Pesquisas em Administração, Universidade Federal de Minas

Gerais - Belo Horizonte - MG, Brasil

Kelen Vanzin Moura da Silva kelenvanzin@uol.com.br

Mestranda em Administração pelo Centro de Pós-Graduação e Pesquisas em Administração, Universidade Federal de Minas

Gerais - Belo Horizonte - MG, Brasil

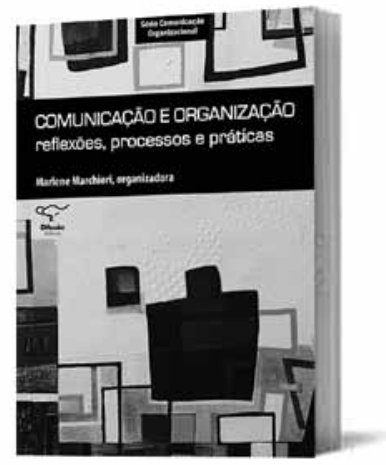

\section{COMUNICACÃ̃O E ORGANIZACẼ̃O: Reflexões, Processos e Práticas}

Marlene Marchiori (Org). São Caetano do Sul: Difusão, 2010. $348 \mathrm{p}$.

O livro Comunicação e Organização: Reflexões, Processos e Práticas, organizado por Marlene Marchiori, apresenta um mosaico teórico-empírico, escrito por importantes pesquisadores, professores e executivos internacionais e nacionais das áreas da administração, comunicação e educação. A obra está segmentada em três partes: (1) o olhar sobre a comunicação e a organização; (2) a comunicação e seus processos nas organizações; e (3) a comunicação e suas práticas nas organizações. Em cada uma delas, é possível defrontar-se com diferentes correntes de pensamento que permeiam a comunicação e a administração, como a neofuncionalista, a interpretacionista e a crítica. Ao longo do livro, o leitor também se depara com a referência a textos de importantes estudiosos desses três campos temáticos, a exemplo de Luhmann (sistemas autopoiéticos), Habermas (ação comunicativa), Deetz (comunicação colaborativa), Putnam e Fairhurst (discurso organizacional), Jarzabkowski (estratégia), Mitchell, Agle e Wood (stakeholders) e Reed (teoria organizacional), sem deixar de lado o mérito dos autores deste livro, que aproximaram a teoria e prática por meio de estudos acerca do fenômeno da comunicação no cotidiano organizacional.

$\mathrm{Na}$ primeira parte do livro, os autores dos capítulos versam sobre as diferentes óticas que permeiam a comunicação. Na perspectiva funcionalista, ela é vista como um instrumento, uma ferramenta das atividades organizacionais, servindo como meio pelo qual os atores transmitem suas intencionalidades discursivas. Já em uma ótica alternativa, como a da Escola de Montreal, a comunicação é vista como o elemento que constitui uma organização. Postula-se que as organizações emergem da comunicação por meio de uma dinâmica de texto-conversação. Seus pesquisadores, como Taylor, Cooren, Van Every, defendem a inversão do termo comunicação organizacional para organização na comunicação.

A temática da estratégia também está no bojo das discussões dessa primeira seção. Um dos prismas destacados diz respeito à estratégia como prática social, que é abordada como processo de construção da realidade por meio das interações, além de levar em consideração que só pode ser compreendida em consonância com o ambiente sociocultural no qual está inserida. O elemento humano, sob a forma de 
ator social, adquire papel primordial nessa construção, pois é com base em percepções, criações e interações desses atores que tais estratégias se materializam. Nesse sentido, a estratégia também pode assumir um caráter processual, cedendo lugar à compreensão de strategizing, entendido como o processo constante de se fazer estratégia por meio da interação dos diversos atores sociais (praticantes) em harmonia com as dimensões da práxis e das práticas. A comunicação constitui, assim, uma realidade inerente a esse processo de construção de estratégia como prática, sendo intrínseca às interações entre os atores.

Isso posto, para que se possa compreender mais amplamente essa dinâmica, cabe destacar a necessidade de reconhecimento e análise de aspectos que se encontram para além da estrutura formal e tangivel das organizações - ou seja, sua face simbólica. A compreensão dessa dimensão ocorre, prioritariamente, por meio da processualidade, na qual é possível considerar as percepções e interpretações dos atores organizacionais sobre os fatos, em um universo paralelo aos processos instrumentais e formais de gestão. Considerar as organizações em um caráter processual, então, significa visualizá-las (também) como em permanente estado de constituição, substituindo, assim, o conceito de organization pelo de organizing. Ou seja, visualizar a organização como um ambiente que abriga fatores formais e informais em um constante processo de (re)construção permite que se compreenda como a relação discurso-organização, bem como o caráter discursivo das organizações, também assume um papel primordial para lidar com esse fenômeno complexo chamado gestão.

$\mathrm{Na}$ segunda parte do livro, os autores apresentam textos que trazem como uma das propostas a comunicação como propulsora de maior transparência, diálogo, participação e entendimento mútuo dentro das organizações. Para tanto, apresentam ao leitor a Teoria da Ação Comunicativa, de Jürgen Habermas, que estabelece o agir comunicativo, pautado na simetria da comunicação, no consenso pelo melhor argumento, na igualdade de participação e no entendimento mútuo. Por essa moldura teórica, apontam-se as distorções da comunicação dentro das organizações e os mecanismos discursivos para a dominação e manutenção do poder. De modo semelhante, aborda-se a Teoria da Comunicação Colaborativa, de Stanley Deetz, pautada na tríade diálogo, entendimento mútuo e colaboração, levando, em última instância, a um ambiente organizacional mais participativo, autêntico e propício à inovação. Por outro lado, ressalta-se que, quando inadequada, a comunicação pode ser analisada como um dos principais motivos de insucesso em projetos e uma das maiores barreiras à eficiência das organizações, conforme os indicadores de gestão organizacional. Em um ambiente interorganizacional, observa-se a possibilidade de relações cooperativas que exigem um compromisso mútuo das empresas envolvidas para se obterem os melhores resultados. Outra temática abordada é a história da comunicação organizacional no Brasil, em que se destaca a Associação Brasileira de Comunicação Empresarial (Aberje) como um de seus pilares e marco, em 1967.

E, por fim, em sua terceira parte, há a interface entre as teorias de comunicação e a prática nas organizações por meio da comunicação interna e externa, na busca da legitimidade social e reputação. Apresentam-se dois casos: o primeiro, da empresa Odebrecht, e o segundo, da Vale do Rio Doce. A co- municação da Odebrecht é descrita por centrar, em primeiro lugar, na valorização da história da empresa, de sua cultura organizacional e na busca de uma legitimação social local, mesmo que a empresa seja multinacional. Seguindo uma proposta de interlocução semelhante, a comunicação na Vale do Rio Doce é apresentada por manter seu foco no entendimento sólido do que é o propósito da empresa e busca o conhecimento em profundidade de todos os stakeholders. O objetivo é a promoção de um diálogo calcado na confiança mútua entre sociedade e empresa e vice-versa, de acordo com a dinâmica de cada território onde a organização atua.

A obra Comunicação e Organização: Reflexões, Processos e Práticas apresenta um quadro diversificado acerca da interdisciplinaridade da comunicação e da administração por meio de uma leitura contemporânea. De modo geral, a obra chama a atenção para a necessidade de se observarem os fenômenos organizacionais de maneira abrangente, considerando suas diversas leituras e abordagens, desde a mais tradicional à mais alternativa, da perspectiva funcionalista às perspectivas simbólica e crítica. A bricolagem de autores clássicos e contemporâneos, explicados e traduzidos para o dia a dia das organizações por pesquisadores, professores, executivos, é o diferencial desta obra. Assim, é possível entender tanto a comunicação como a administração sob o prisma da processualidade, oferecendo uma leitura alternativa à ótica instrumental e linear dessas duas ciências, salvo alguns casos em que se reforça a ideia de comunicação apenas como meio, ferramenta para a administração, levando a um diálogo mais estreito, voltado apenas aos interesses de alguns stakeholders, principalmente no que tange à gestão e à maximização dos lucros. 